\title{
Design, fabrication and testing of micro-channel solar cell thermal (MCSCT) tiles in indoor condition
}

\author{
Sanjay Agrawal ${ }^{1, *}$, S. C. Solanki ${ }^{1}$, G. N. Tiwari $^{1}$ \\ ${ }^{1}$ Centre for Energy Studies, Indian Institute of Technology Delhi, New Delhi, India \\ * Corresponding author. Tel: +91 9911428863, Fax: +91 1126591251,E-mail: sanju.aggrawal@gmail.com
}

\begin{abstract}
In this paper design, fabrication and testing of micro-channel solar cell thermal (MCSCT) tiles has been discussed. Solar simulator for an indoor testing of micro-channel solar cell thermal tiles has also been developed. Fabricated MCSCT tile consists of single solar cell, micro- channel and fan for extraction of heat from bottom of solar cell. Single MCSCT tile has been termed as case-I. Similarly, two MCSCT tiles which are connected in series have been termed as case-II. The performance evaluation in terms of electrical efficiency, thermal gain, overall thermal energy and overall exergy of both cases has been carried out in indoor conditions on various intensities. It has been also found that the electrical efficiency is higher in case-I as compared to caseII. On the other hand the thermal out put of case-II is higher than case-I on same intensity and mass flow rate. It has been found that the average electrical and thermal efficiency of newly designed and fabricated MCSCT tile is $12.4 \%$ and $35.7 \%$ respectively. This economical solar simulator can be used by manufactures for testing of different type of photovoltaic tile as well as photovoltaic modules.
\end{abstract}

Keywords: Full Photovoltaic thermal tile, Micro-channel, Solar simulator.

\section{Nomenclature}

$A_{c}$ Area of MCSCT tile .$m^{2}$

E Electrical power .. $W$

Ex Exergy. $k W$

I(t) Intensity. $\mathrm{Wm}^{-2}$

$\dot{m}_{f}$ Mass flow rate of $\mathrm{Kg} \mathrm{s}^{-1}$

$C_{f}$ Specific heat of air $J k g^{-1} K^{-1}$

$\dot{Q}_{u}$ Rate of useful energy ..$k W$

$V \quad$ velocity of air inside micro-channel ..... $\cdot \mathrm{s}^{-1}$

$V_{\text {oc }}$ Open circuit voltage ...Volt

$V_{L}$ Load voltage Volt

$I_{s c}$ Short circuit current Amp

$I_{L} \quad$ Load current Amp
$T_{\text {foN }}$ Outlet fluid i.e air temperature of $N^{\text {th }}$ tile....... ${ }^{\circ} \mathrm{C}$

$T_{f i}$ Inlet fluid i.e air temperature ...... ${ }^{0} \mathrm{C}$

$T_{a}$ Ambient temperature ....... ${ }^{\circ} \mathrm{C}$

Subscript

$n$ number of MCSCT tile

$f \quad$ Fluid

c solar cell

o outlet

Greek letter

$\eta_{\mathrm{e}}$ Electrical efficiency

$\eta_{\text {th }}$ Thermal efficiency

\section{Introduction}

Photovoltaic technology (PV) is commonly known as one of the promising renewable energy technologies. It is well known fact that electrical efficiency falls as the temperature of the photovoltaic cells rises. The efficiency of the system falls about 0.0045 when cells temperature increased by $1^{\circ} \mathrm{C}$ [1]. The generation of both thermal and electrical energy simultaneously is known as hybrid photovoltaic thermal technology (PVT). Solar hybrid PVT system can generate more energy per unit area compared to the system of solar panel and thermal collector separately side by side [2]. Sopian et al. [3] and Prakash[4] have analyzed single pass solar collector with open channel absorber. The double pass solar collector with upper and lower channels has been fabricated by Garg et al. [5] and cox et al. [6]. Erdil et al. [7] fabricated a hybrid system consisting of a PV module and a solar thermal collector and tested it for energy collection in Cyprus. They found out that the ratio of gain to losses for 
thermal energy is 50 times the electrical energy, which was measured between the periods of 12:00 and 16:00 hour.

An experiment to compare the efficiency of an integrated photovoltaic thermal solar (IPVTS) system with conventional solar water heater was carried out by Huang et al.[8]. Tonui and Tripanagnostopoulos [9] reported a cheap and simple method to cool the photovoltaic thermal (PVT) system. Sopian et al. [10] developed and tested a double pass PVT solar collector, which is suitable for solar drying purposes. Design, development and performance monitoring of a photovoltaic-thermal (PVT) air collector has been studied by Niccolo et al. [11] and they found that the simulation model, developed under this program predicts quite well the thermal and electrical performance of a PVT collector. The model, in general, can be utilized for any set of design and operational parameters for evaluating the performance of front cover direct flow PVT air collector, semitransparent with different solar cell density (i.e. the ratio between the area of the cells and the total laminate surface) or completely opaque (e.g. standard PV laminate like those employed in the experimental campaign presented). The relations between energy and exergy, energy and sustainable development, energy policy making, exergy and the environment and exergy in detail are reported by Dincer [12]. Energy and exergy analysis of hybrid micro-channel photovoltaic thermal module has been carried by Agrawal and Tiwari [13] and they concluded that micro-channel photovoltaic thermal module gives better results.

Till now, most researchers have carried out the electrical and thermal performance analysis on PVT system consisting of PV module and a duct. The objective of this study is to develop a micro PVT system known as MCSCT tile and solar simulator for testing of MCSCT tile. The performance evaluation of MCSCT tiles has been carried out on various intensity and constant mass flow rate. Comparative studies have been carried out between single MCSCT tile (case I) and two MCSCT tile connected in series (case II).

\section{Experimental setup}

Experimental test rig consisting of MCSCT tiles and solar simulator to test the performance of the MCSCT tiles on various operating parameter.

\subsection{Micro-channel solar cell thermal tile}

The MCSCT tile as shown in Fig. 1a consists of a single solar cell, rated at $2.2 \mathrm{Wp}$ having $0.125 \mathrm{~m}$ width and $0.125 \mathrm{~m}$ length and mounted on a rectangular wooden channel. The channel has a dimension $0.125 \mathrm{~m}$ in length, $0.125 \mathrm{~m}$ in width and $0.005 \mathrm{~m}$ in depth. Small holes are provided at the cross edge of the channel to pass the hot air for utilization and also to connect other the MCSCT tile in series combination. The wooden micro-channel has been sealed with putty and adhesive tape to avoid air leakage. Similarly, another one MCSCT tile are fabricated and connected in series through PVC pipe. MCSCT tile are arranged in such a manner that outlet of first tile is inlet of second .The MCSCT tile have been placed on a mild steel platform with a mechanism for up and down movement for varying the light intensity. A DC fan of $6.0 \mathrm{~V}$ and $0.1 \mathrm{~A}$ has been used for forced mode of operation to make flow the air through the channel of tile. 


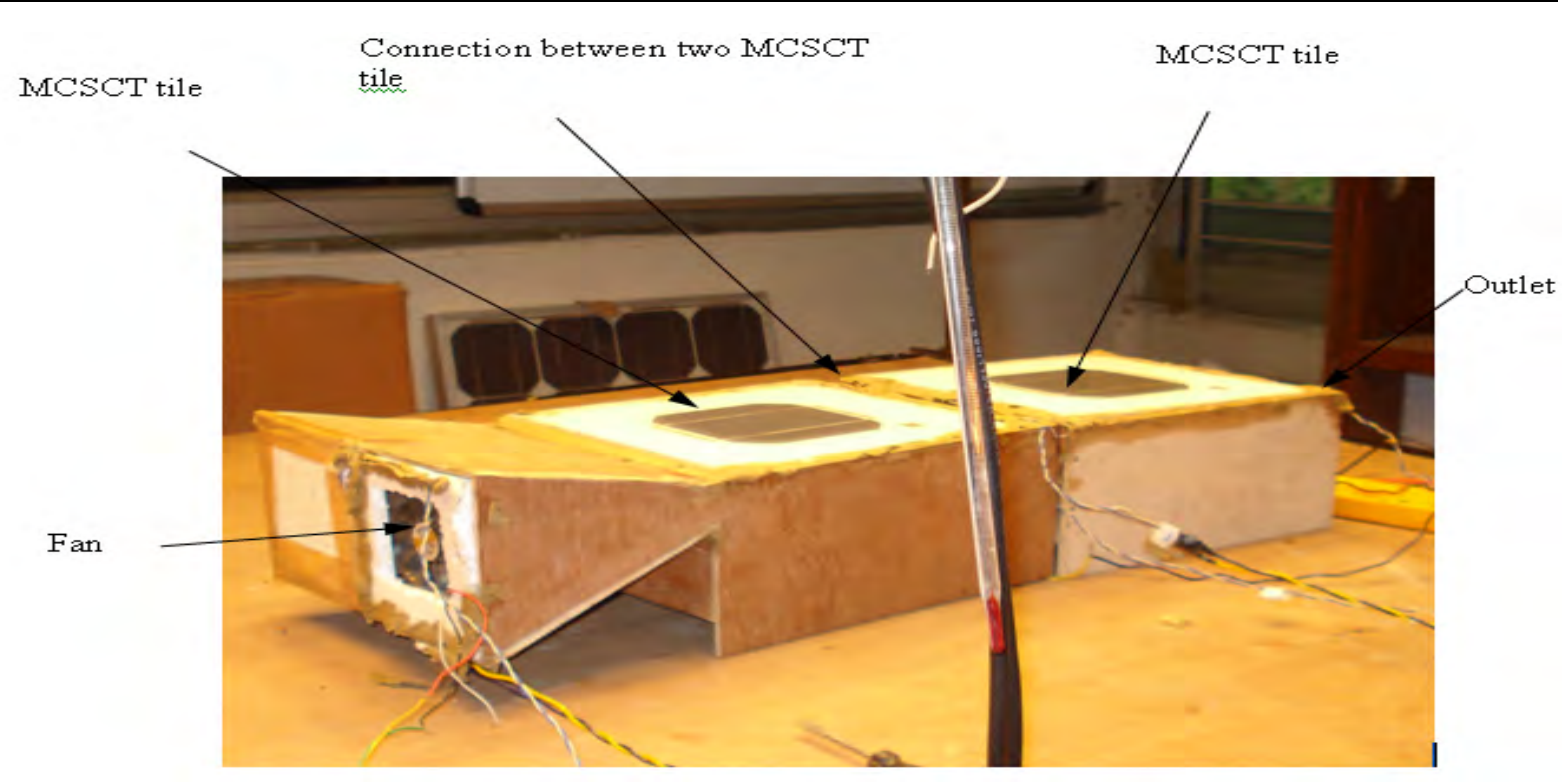

Fig.1a. Photograph of hybrid micro-channel solar cell thermal (MCSCT) tiles

\subsection{Solar simulator}

A solar simulator (Fig.1b) with a 3-phase lamp array is employed to imitate the necessary solar irradiation in the testing of micro-channel solar cell thermal tile. The solar simulator has 28 tungsten halogen lamps (Philips manufactured; Model: 392472) each having 500W, 9000 lumens and rated at $240 \mathrm{~V}$ and $11 \mathrm{~A}$. The halogen lamps are arranged in $7 \times 4$ matrices for uniform distribution of irradiance on the MCSCT tile. An exhaust fan has also been provided in the laboratory wall to avoid the overheating of cell by withdrawing the thermal energy associated with it. The available area for testing is $1 \times 2 \mathrm{~m}$.The height of the simulator from the floor is $200 \mathrm{~cm}$. The distance between platform and halogen lamp is $100 \mathrm{~cm}$. Intensity of simulator can be varied between $300 \mathrm{~W} / \mathrm{m}^{2}$ to $1000 \mathrm{~W} / \mathrm{m}^{2}$ by decreasing the gap of halogen lamp and platform.

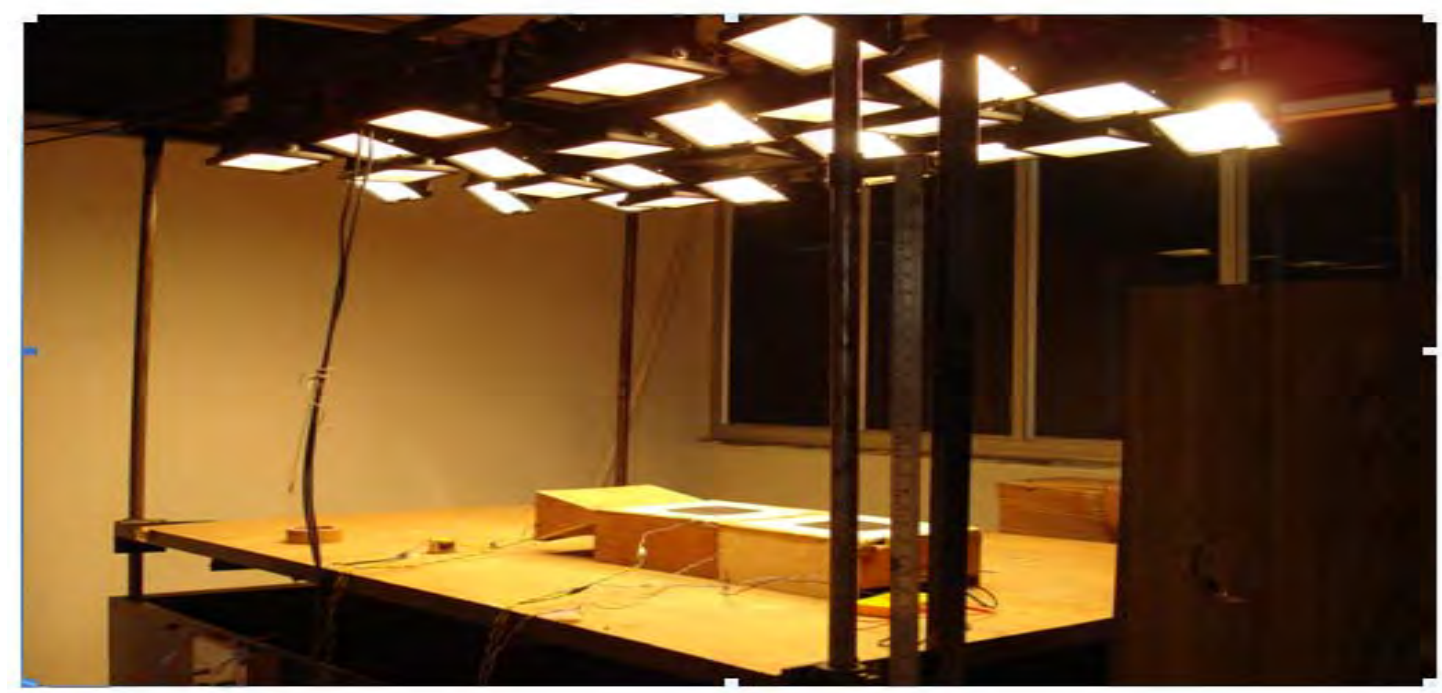

Fig.1b. Photograph of solar simulator with micro-channel hybrid MCSCT tiles

\subsection{Instrumentation}

The following instruments have been used during the experimentation: 
(i)Thermocouples: A calibrated copper-constantan thermocouples and a digital temperature indicator are used to measure the temperature of several locations, namely, back surface, inlet and outlet air temperature of each collector and final outlet air temperature. Digital temperature indicator has least count of $0.1^{\circ} \mathrm{C}$.

(ii) Solarimeter: The intensity of solar radiation is measured by the solarimeter having a least count of $20 \mathrm{~W} / \mathrm{m}^{2}$, manufactured by CEL, India Ltd, Sahibabad (UP), India. The solarimeter has been calibrated with the standard pyranometer.

(iii) Anemometer (Lutron-AM4201): It is a conventional instrument used to measure the velocity of flowing air. The least count of the instrument is $0.1 \mathrm{~m} / \mathrm{s}$.

(iv) Infrared thermometer: The infrared thermometer is used to measure the top surface temperature of PV module. The least count of the instrument is $0.1^{\circ} \mathrm{C}$.

(v) Clamp meter: It is used for measurement of a current and voltage. The least count of the instrument is $0.1 \mathrm{~A}$ and $0.1 \mathrm{~V}$.

\section{Methodology}

The experiments have been conducted on various intensity namely 600,700 and $800 \mathrm{~W} / \mathrm{m}^{2}$ and maintaining the constant mass flow rate $(0.000145 \mathrm{~kg} / \mathrm{s})$ to observe the effect of intensity on different performance parameters of single MCSCT tile (case-I) and two MCSCT tile connected in series (case-II). The following mathematical expressions have been used for analysis:

\subsection{Electrical efficiency}

The electrical efficiency of micro-channel solar cell thermal (MCSCT) tile can be obtained as, Tiwari [14],

$$
\eta_{\mathrm{e}}=\frac{F F \times V_{o c} \times I_{s c}-I_{L} \times V_{L}}{N \times A_{c} \times I(t)}
$$

where fill factor (FF) is a measure of sharpness of the $I-V$ curve. It indicates how well a junction was made in the cell and how low is the series resistance. It can be lowered by the presence of series resistance and tends to be higher whenever the open circuit voltage is high

\subsection{Instantaneous thermal efficiency}

An instantaneous thermal efficiency of hybrid micro-channel solar cell thermal tile can be obtained as, Tiwari [14] and Duffie and Beckman [15] ,

$$
\eta_{\text {th }}=\frac{\dot{Q}_{U, N}}{N A_{c} I(t)} \quad \text { where } \dot{Q}_{U, N}=\dot{m}_{f} C_{f}\left(T_{f o N}-T_{f i}\right)
$$

\subsection{Over all thermal energy}

The energy analysis is based on the first law of thermodynamics, and the expression for overall thermal gain can be defined as, 
$\sum \dot{Q}_{u, \text { overall }}=\sum \dot{Q}_{u, \text { thermal }}+\frac{\sum \dot{Q}_{u, \text { electrical }}}{\eta_{\text {cpower }}}$

where $\eta_{\text {cpower }}$ is a conversion efficiency of thermal power plant which depends upon quality of coal ( $\eta_{\text {cpower }}=0.38$ for good quality of coal).The range of $\eta_{\text {cpower }}$ is varying between 0.20-0.40.

This electrical energy has been converted to equivalent thermal by using electric power generation efficiency conversion factor as $0.20-0.40$ for a conventional power plant, Huang et al. [8] and it depends on quality of coal. Usual value of this factor is taken as 0.38 for conversion

\subsection{Overall exergy}

The exergy analysis is based on the second law of thermodynamics, which includes accounting the total exergy inflow, exergy outflow and exergy destructed from the system.

$\dot{E} x_{\text {overall }}=\dot{E} x_{\text {thermal }}+\dot{E} x_{\text {electrical }}$

Where $\dot{E} x_{\text {thermal }}=\dot{Q}_{U, N}\left[1-\frac{T_{a}+273}{T_{f o}+273}\right]$ and $\dot{E} x_{\text {electrical }}=\left[\frac{\eta \times A_{c} \times I(t)}{1000}\right]$

\section{Results and discussions}

In a series of experiments conducted, data have been recorded at different intensity for comparative evaluation for case-I and case-II. The experimental results of outlet air temperatures for both configurations (case-I and case -II) at various intensities $600 \mathrm{~W} / \mathrm{m}^{2}, 700$ $\mathrm{W} / \mathrm{m}^{2}$ and $800 \mathrm{~W} / \mathrm{m}^{2}$ have been shown in Fig. 2. It has been observed that outlet air temperature of case-II is higher as compared to case-I at same intensity and constant mass flow rate $(0.000145 \mathrm{~kg} / \mathrm{s})$ and $\mathrm{T}_{\mathrm{fi}}=38{ }^{\circ} \mathrm{C}$. The Effect of intensity on outlet air temperatures of MCSCT tiles has also been shown in Fig. 2. One can be concluded that as intensity increases, the outlet air temperature increases for case-I. Similarly trends have also been observed for case-II. It has also been observed that as there is increase in duration of time, outlet air temperature is increased and approaches the steady state condition after approximately two hours. The maximum outlet air temperature of $90^{\circ} \mathrm{C}$ and $89^{\circ} \mathrm{C}$ on intensity of $800 \mathrm{~W} / \mathrm{m}^{2}$ have been observed for series combination and single MCSCT tiles respectively.

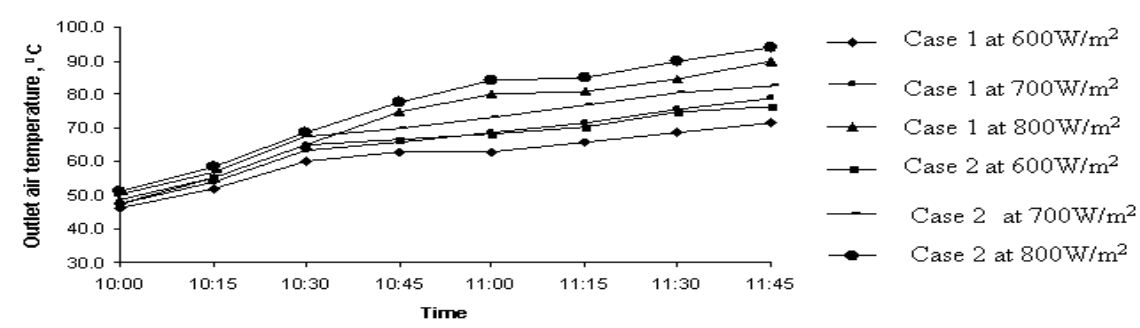

Fig. 2 . Variation of outlet air temperature at various intensity

Fig. 3 shows the time variation of solar cell temperature at different intensities $600 \mathrm{~W} / \mathrm{m}^{2}, 700$ $\mathrm{W} / \mathrm{m}^{2}$ and $800 \mathrm{~W} / \mathrm{m}^{2}$ for both cases. It can be seen that solar cell temperature of case-II is 
significantly higher than case-I at lower intensity $\left(600 \mathrm{~W} / \mathrm{m}^{2}\right)$ but at higher intensity (700 and $800 \mathrm{~W} / \mathrm{m}^{2}$ ) the solar cell temperature of both cases are nearly same. It is obviously due to very small heat carrying capacity of air.

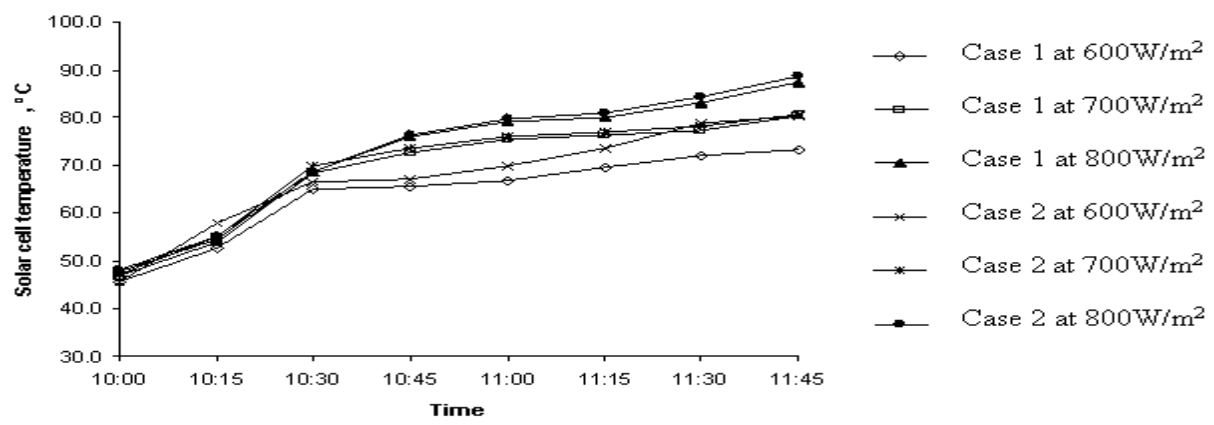

Fig. 3. Variation of solar cell temperature at various intensity

The electrical and thermal efficiency have been calculated with help of Eq. (1) and Eq. (2) for both cases at various intensities. Variations of electrical and thermal efficiency with respect to time have been shown in Fig. 4 and Fig. 5, respectively It has been found that as intensity increases, electrical efficiency decreases because of rise in cell temperature and this result is in accordance with result reported by earlier researchers, Zondag et al.[1]. The electrical efficiency for case-I is higher than case-II at lower intensity due to lower cell temperatures. Electrical efficiency in the range of $13.6 \%$ to $11.7 \%$ and $13.6 \%$ to $11.1 \%$ has been observed for case-I and case-II respectively. It has been found that as intensity increases, outlet temperature of MCSCT tile also increases and due to increase in outlet temperature , thermal efficiency is increased because inlet temperature $\mathrm{T}_{\mathrm{fi}}=38{ }^{0} \mathrm{C}$ is maintained constant.

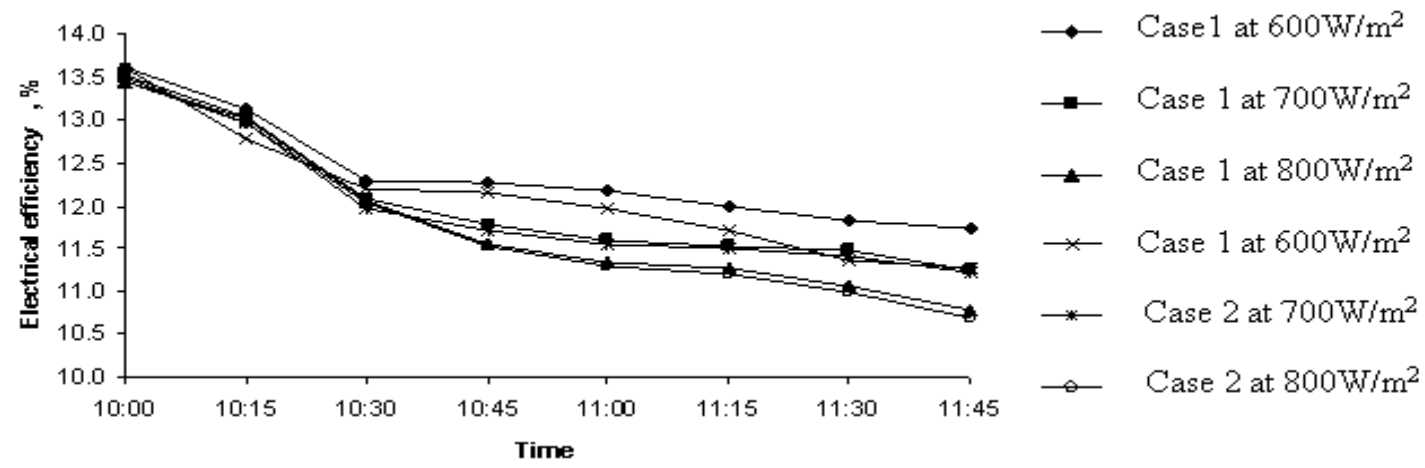

Fig. 4. Variation of electrical efficiency at various intensity

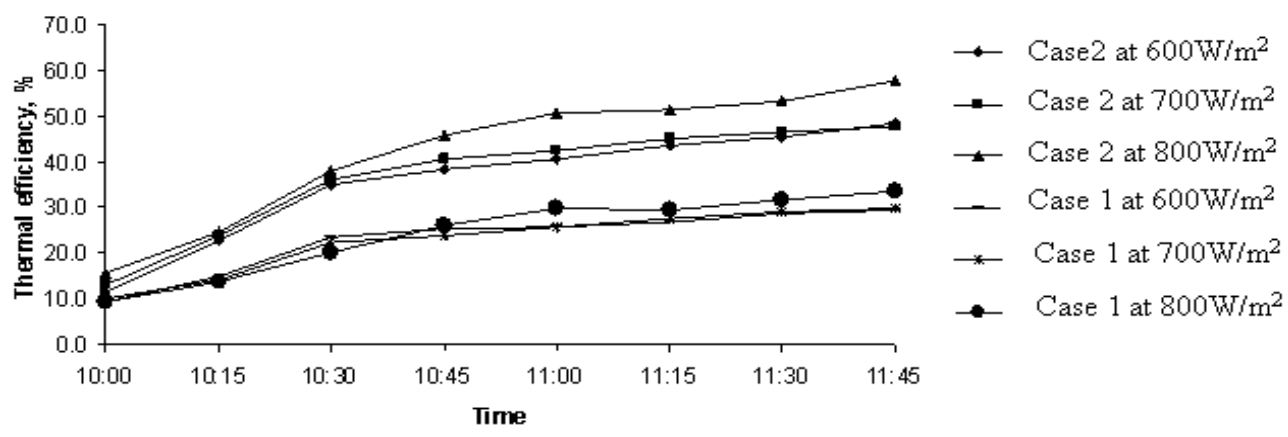

Fig.5. Variation of thermal efficiency at various intensity 
Overall thermal energy and overall exergy have been calculated with help of Eq. (3) and Eq. (4) for both cases at various intensities Fig.6 shows that the variation of overall thermal energy at various intensities. It has been observed that increase in intensity will increase the overall thermal energy for MCSCT tiles for both cases and one can also conclude that overall thermal energy of series connected MCSCT tiles (case II) is significantly higher than single MCSCT tile (case I) .Similarly trends has also seen for overall exergy for both case as shown in Fig. 7.

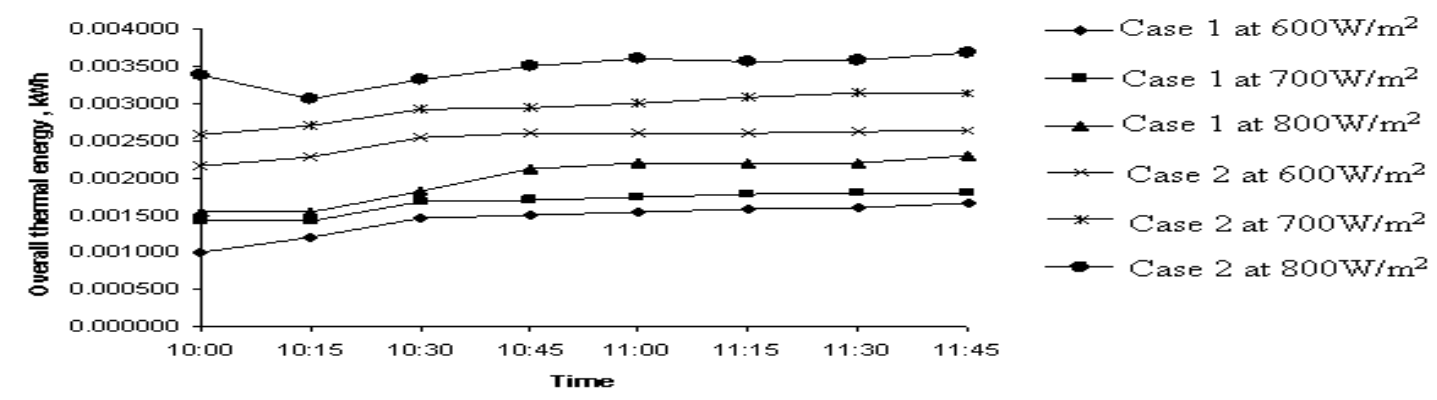

Fig. 6.Variation of overall thermal energy at various intensity

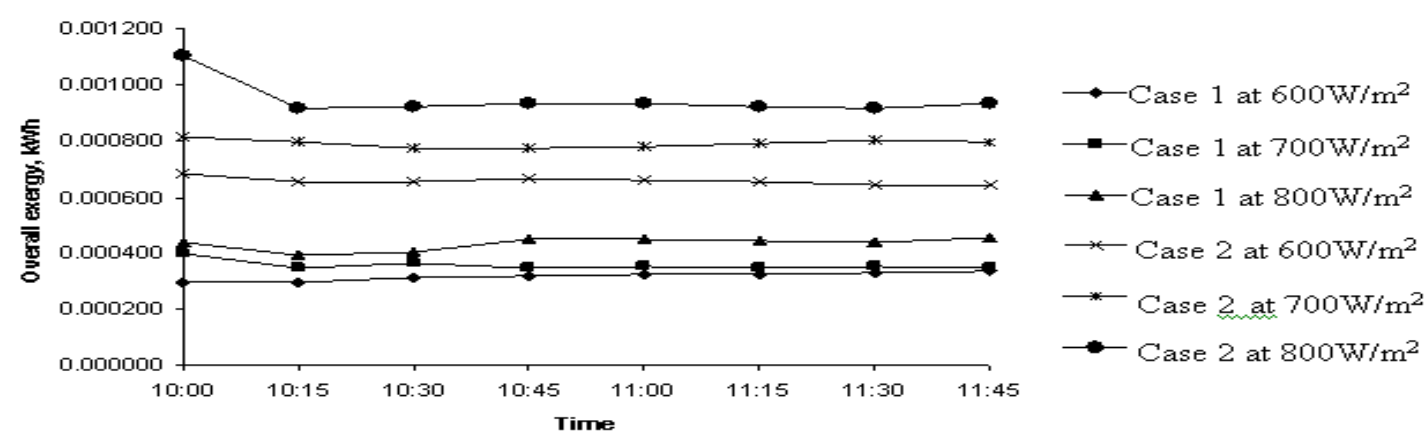

Fig. 7. Variation of overall exergy at various intensity

\section{Conclusions}

It has been concluded that the average electrical and thermal efficiency of newly designed and fabricated MCSCT tile is $12.4 \%$ and $35.7 \%$ respectively. This new present setup would have beneficial effect of permitting much less expensive installation for testing of PV tile. Hence the test procedure can be used by manufacturers for testing of different type of PV tiles and combination of PV tiles in order to optimize its products for better efficiency. The Limitations of MCSCT tile are ohmic losses in solar cell, temperature gradient along the thickness of solar cell.

\section{References}

[1] H. A. Zondag, D. W. de Vries, W. G. J. van Helden, R. J. C. van Zolingen, A. A. van Steenhoven, The thermal and electrical yield of a PV thermal collector, Solar Energy, 72 (2), 2002, pp.113-128.

[2] P.G. Charalambous, G.G. Maidment, S.A. Kalogirou, K. Yiakoumetti, Photovoltaic Thermal (PVT) collectors: A review, Applied Thermal Energy 27, 2007, pp. 275- 286. 
[3] K. Sopian, K.S. Yigit, H. T. Liu, S. Kakac , T. N. Veziroglu, Performance analysis of photovoltaic thermal air heaters, Energy Conversion and Management 37,1996, pp. 1657-1670.

[4] J. Prakash, Transient analysis of photovoltaic thermal solar collectors for cogeneration of electricity and hot air/water, Energy Conversion and Management 35, 1994, pp. 967972.

[5] H. P Garg, R. K Agarwal, A. K. Bhargava ,Study of a hybrid solar system-solar air heater combined with solar cells, Energy Conversion and Management 31, 1991, pp. 471-479.

[6] C. H. Cox III, P. Raghuraman, Design considerations for flat-plate photovoltaic/thermal collectors, Solar Energy 35, 1985, pp. 237-242.

[7] E. Erdil, M. Ilkan, F . Egelioglu , Renewable energy resources as an alternative to modify the load curve in Northern Cyprus, Energy 33, 2008, pp.1241 -2008.

[8] B. J. Huang, T. H. Lin, W. C. Hung, F S. Sun,Performance evaluation of solar photovoltaic/thermal systems, Solar Energy 70, 2001, pp 443-448.

[9] J. K. Tonui, Y. Tripanagnostopoulos , Air-cooled PVT solar collectors with lowcost performance improvements, Solar Energy 81, 2007,pp. 498-511.

[10]K. Sopian, H. T. Liu, S. Kakac, T. Veziroglu, Performance of a Double Pass Photovoltaic Thermal Solar Collector Suitable for Solar Drying Systems, Energy Conversion and Management 41, 2000, pp. 353 - 365.

[11] Niccolo, C. Giancarlo, V. Francesco, Design, development and performance monitoring of a photovoltaic-thermal (PVT) air collector, Renewable energy 33, 2007,pp. 914-927.

[12] Dincer, The role of exergy in energy policy making, Energy Policy 30, 2002, pp. 137149.

[13] S. Agrawal, G. N. Tiwari, Energy and exergy analysis of hybrid micro-channel photovoltaic thermal module, Solar Energy, 85, 2011, pp 356-370.

[14] G. N. Tiwari, Solar Energy: Fundamentals, Design, Modeling and Applications. Narosa Publishing House New Delhi, 2004.

[15] J. A. Duffie, W. A. Beckman, Solar Engineering of Thermal Processes, John Wiley and Sons, New York, 1991 